\title{
Grassroots innovation: The state of the art and future perspectives
}

DOI:

10.1016/j.techsoc.2018.06.008

\section{Document Version}

Accepted author manuscript

Link to publication record in Manchester Research Explorer

\section{Citation for published version (APA):}

Hossain, M. (2018). Grassroots innovation: The state of the art and future perspectives. Technology in Society. https://doi.org/10.1016/j.techsoc.2018.06.008

\section{Published in:}

Technology in Society

\section{Citing this paper}

Please note that where the full-text provided on Manchester Research Explorer is the Author Accepted Manuscript or Proof version this may differ from the final Published version. If citing, it is advised that you check and use the publisher's definitive version.

\section{General rights}

Copyright and moral rights for the publications made accessible in the Research Explorer are retained by the authors and/or other copyright owners and it is a condition of accessing publications that users recognise and abide by the legal requirements associated with these rights.

\section{Takedown policy}

If you believe that this document breaches copyright please refer to the University of Manchester's Takedown Procedures [http://man.ac.uk/04Y6Bo] or contact uml.scholarlycommunications@manchester.ac.uk providing relevant details, so we can investigate your claim.

\section{OPEN ACCESS}




\title{
Grassroots innovation: The state of the art and future perspectives
}

\author{
Technology in Society (forthcoming)
}

\author{
Mokter Hossain, PhD \\ Marie Curie Individual Research Fellow \\ Manchester Institute of Innovation Research \\ Alliance Manchetser Business School \\ The Univeristy of Manchester \\ Denmark Road Building \\ M13 9SS UK \\ mokter.hossain@manchester.ac.uk
}

\begin{abstract}
Drawing on 87 articles retrieved through a systematic literature review approach, this study aims to develop a comprehensive understanding of grassroots innovations (GIs). It synthesizes the state-of-the-art research on GIs and considers various sectors, the tensions between three different facets of grassroots movements (GMs), and the main forces that drive or hinder GMs. The study finds that community energy, community currency, cohousing, agriculture, and organic food are dominant sectors for grassroots innovations, while GMs work under the tension of three facets: scaling up, sustainability, and success. This study also identifies the main driving forces and hindrances for GMs. Based on the limitations and identified gaps in the research, this study suggests avenues for future research.
\end{abstract}

Keywords: grassroots innovation; grassroots movements; sector; scale up; driving and hindering forces; sustainability

\section{Introduction}

Grassroots innovation (GI) literature is already two decades into its journey (Hossain, 2016). GI plays a pivotal role in the move toward sustainable production and consumption (Grabs et al., 2016). While it initially received very limited attention from scholars, there has been a surge in studies on it in recent years. GI is defined as "a network of activists and organizations generating novel bottom-up solutions for sustainable development and sustainable consumption; solutions that respond to the local situation and the interests and values of the communities involved" (Seyfang and Smith, 2007, p. 585). GI is an umbrella concept for a wide range of movements, such as cooperatives, voluntary associations, informal community groups, voluntary labour, and the social economy (Seyfang and Smith, 2007). It emerges from experience, knowledge, and skills that are embedded in the individual and community levels without formal education and research (Reinsberger et al., 2015). Grassroots movements (GMs) based on GIs are well aware of the types of innovations that are suitable for sustainability in their localities. GMs are 
movements that emerge from the local level with a bottom-up approach and diffuse throughout the state and at the national level.

As GIs emerge, they embrace social, cultural and ethical values, whereas mainstream innovations (MIs) are developed for commercial value (Monaghan, 2009). Common examples of GIs include community energy generation, community currencies, cohousing, organic foods, the recycling of local materials, community services, local waste management, and local agriculture (Smith et al., 2014). Cities are becoming smarter and more sustainable (Vergragt et al., 2016), and cleantech entrepreneurs and new business models are receiving increasing attention from academics, practitioners, and policy makers. GIs therefore play a crucial role in the transformation to sustainability.

While GMs are small in scale, they contribute significantly to sustainability (Phelps, 2013). GIs and MIs complement each other (Ornetzeder and Rohracher, 2013), yet mainstream research and development initiatives consider GIs as a peripheral agenda (Jain and Verloop, 2012). Some scholars argue that GIs actually have a greater potential contribution to sustainability than MIs (White and Stirling, 2013). According to Seyfang and Longhurst (2016), GIs can be distinguished from MIs for the following reasons: the main aim of GIs is to solve societal problems; GIs are created through values and culture; GIs work under a community ownership structure; and GIs take place mainly at the individual, group, and societal levels (Grabs et al., 2015), with grants, mutual exchanges, and voluntary labour being the main sources of funding (Heiskanen et al., 2015).

Despite over two decades of research and an increasing relevance to society, there is no systematic literature review of the GI literature aside from a recent review article by Hossain (2016) that thematically analysed various facets of this phenomenon. This study explores issues that have not explored previously. There is no synthesis of the sectors wherein grassroots innovation prevalent. Grassroots movements experience tensions which have not been synthesized in the current literature. Moreover, driving forces and hindrances of grassroots innovations are missing in the literature. Hence, applying a systematic literature review approach, 87 articles have been retrieved from the ISI Web of Science and Scopus. These two are the main databases of quality articles and cover almost all contributory articles. This study aims to develop a comprehensive understanding of GIs by synthesizing the state-of-the-art research into GIs and considering the dominant sectors, the tensions between the different facets of GMs, and the main forces that drive or hinder GMs. The aim of the study is accomplished by exploring the following issues:

(a) A sectoral analysis of the grassroots innovation literature.

(b) The triple tensions of grassroots innovation: scaling up, sustainability, and success.

(c) Driving forces and hindrances for grassroots innovations.

This paper has been structured as follows. The following section elaborates the method, which comprises the definition of the scope of the analysis, classification context, and material evaluation, followed by the collecting, extracting, synthesizing and reporting of publications. The next section then synthesizes the GI literature, while the final section discusses the implications, as well as the limitations of this research and avenues for future research.

\section{Research method}


This study applies a systematic literature review (SLR) approach (Hossain, 2016). SLR differs from the traditional review approach because it is scientific, transparent, unbiased, exhaustive, and replicable. As suggested by Tranfield et al. (2003), a three-step approach was applied here: (1) planning the review, (2) conducting the review, and (3) reporting and disseminating. In step one (planning the review), we focus on GI and its key research areas. We consider only articles with a clear focus on GI. In the second step (conducting the review), we search for occurrences of "grassroots innovation" and "grassroots movement" in the titles, abstracts, and keyword lists of articles (Annarelli et al., 2016; Hossain and Anees-ur-Rehman, 2016). Two databases, namely the Web of Science and Scopus, were searched to find relevant articles following the approach of Hossain (2016). These two databases are well-regarded as sources for good quality articles. For the inclusion criteria, we selected articles written in English and published in journals (Annarelli et al., 2016).

The search for articles started with the Web of Science database. Using "grassroots innovation" and "grassroots movements" as search terms, 177 records were retrieved from this database. Subsequently limiting these to peer-reviewed articles written in English with the keywords mentioned in the title, abstract and keyword list brought the number of articles down to 42. A similar approach for the Scopus database resulted in 61 additional articles. Thus, a total 103 articles were found in these two databases. After careful reviewing the complete articles, 16 articles were excluded for not being relevant, leaving 87 articles for consideration in this study.

In the third step (reporting and disseminating) we report the thematic analysis. After selecting the final set of articles, all articles were downloaded and stored in a temporary folder. Next, the articles were uploaded to the Atlas.ti platform, which is a very effective program for textual analysis (Hossain, 2016). We used the inductive approach in order to synthesize the literature, because this is an appropriate way to condense extensive and varied texts into a summarized format (Thomas, 2006). By thoroughly reading each article on Atlas.ti, key information was coded under various themes. We identified the main sectors for grassroots innovation and knowledge about those sectors. Secondly, we coded the selected articles based on the three themes of scaling up, sustainability, and success (the 3Ss), which we refer to collectively as the triple tensions of GI. Finally, we analysed the GI literature based on two key elements: driving forces and hindering forces. The coding process was iterated to achieve a rich compilation of the existing knowledge (Hossain, 2016).

\section{Analysis}

\subsection{Sectoral Analysis}

GIs are present mainly in sectors such as energy, agriculture, organic food, cohousing (Smith, 2006), and community currency (Longhurst, 2012). There have also been studies for other sectors, such as waste management, recycling, and community service. In this section, we explore the five major sectors of GIs: community energy, community currency, cohousing, agriculture, and organic food. 


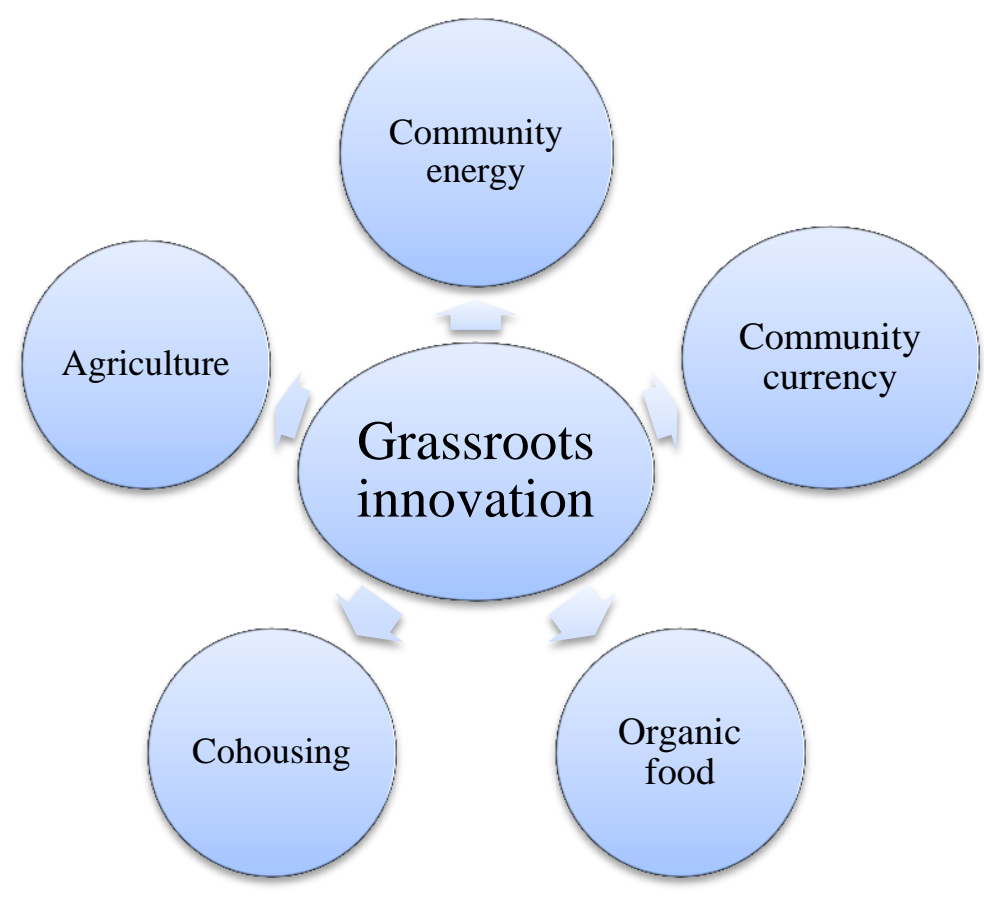

Figure 1: Major sectors of grassroots innovation

Community Energy: Community energy (CE) movements are commonplace, especially in urban settings. They are gaining growing attention as a promising source of sustainable energy (Hargreaves et al., 2013). These movements are not new and actually date back at least several decades. Community energy (CE) is defined as locally owned, locally sited renewable energy with components of community engagement that go beyond mere investment and shareholding relationships (see Klein and Coffey, 2016). CE refers to energy projects where communities have a high degree of ownership and control (Seyfang et al., 2014). Evidence of this trend can be seen in the recently emerging civic community energy concept, where volunteers collectively set up and run decentralized projects to produce and consume sustainable energy (de Vries et al., 2015). According to Vergragt and Brown (2012), every municipal energy plan should emphasize the reduction of energy consumption. CE offers a complementary model to the top-down mainstream energy (Klein and Coffey, 2016). Projects can operate in several modes, such as cooperatives, charities, development trusts, and donations (see Klein and Coffey, 2016). The interplay between social, symbolic, and technological innovations is a key to the success of civic energy communities (de Vries et al., 2016). There are thousands of CEs in Europe that promote renewable energy and reduced energy consumption (see Oteman et al., 2014). Some scholars argue that there are over $700 \mathrm{CE}$ movements in Germany, and around 500 in the Netherlands (de Vries et al., 2015). Some other European countries, such as the UK, Italy, France, Spain, Denmark, and Sweden are also at the forefront of community energy practices. Numerous intermediaries also support CEs. For example, Hargreaves et al. (2013) found at least 94 active intermediaries in the UK to support CEs.

Scholars argue that communities may generate $50 \%$ of their electricity by 2050 in the UK. Communities develop local energy systems by implementing energy technologies and engaging non-technical actors 
(Walker and Cass, 2007). CEs collectively organize loosely related components to develop a local energy system that meets the energy needs of the community (Peine et al., 2014). They need to adapt, modify, and update their support service for their movements (Hargreaves et al., 2013). CEs are generally smallscale projects that are unattractive for large energy firms (Hess, 2013). Sustainable energy models are often linked to local ownership through local government and cooperatives, while homeowners may remain a marginal player (Hess, 2013; Hodson and Marvin 2010). However, a successful community energy model for homeowners can transform into a commercial venture (Hess, 2013).

CE is considered a new way to accomplish a sustainable energy system, but real evidence for these movements is underdeveloped and fragmented (Seyfang et al., 2013). Compared to other GMs, CE is more effective in spurring innovation (Hoppe et al., 2015). However, it suffers from numerous problems, such as reliance on volunteers, a lack of skilled workers and professionals, the lack of an established infrastructure, and a lack of instructional supports, alienation of the community, and a loss of popularity among local citizens (Hoppe et al., 2015). A key challenge for CE initiatives is to move from the community level to mainstream adoption (Yalçın-Riollet et al., 2014). Moreover, projects need differently skilled local workforces, research support, and help for intellectual property achievement (Creech et al., 2014). Despite these many challenges, however, CEs are thriving around the world.

Community Currency: Community currencies (CCs) serve economically marginalized people (Collom, 2005). CCs are parallel exchange systems that have emerged in civil societies around the world over the last 30 years (Seyfang and Longhurst, 2013a). Indeed, Seyfang and Longhurst (2013b) found that community currency is widely used all around the globe. However, their use is highly concentrated in Europe (68.3\%) followed by Asia (16.6\%), and North America (9.8\%). The diverse range of community currencies includes service credits, mutual exchanges, local currencies, and barter markets (Seyfang and Longhurst, 2013a). In CC movements, individuals usually join a community for an interest-free loan (Seyfang and Longhurst, 2013a). The goals of CCs include promoting local economies, providing incentives to trade with local actors (so money circulates locally), and increasing the local financial multiplier (Seyfang and Longhurst, 2016). Local currencies have several advantages, such as (1) they are used to purchase more readily available locally produced goods and services; (2) they induce the development of a steady-state economy through recycling of resources; and (3) localized economies are more resilient to external influences (e.g., currency fluctuations) (see North, 2005).

CCs are radical experiments, and potential users need reassurance. Their expectations need to be fulfilled if they are to continuously participate in various programs (Seyfang and Longhurst, 2016). A study found service credits to be the most common (50\%) type of community currency. This aims to build social capital, neighbourly support, social care, and reciprocal volunteering schemes mainly at the community level (Seyfang and Longhurst, 2013b). The second most prominent type of community currency is mutual exchange, followed by geographically-bounded, paper-based local currencies (Seyfang and Longhurst, 2013a). Some people use paper currency notes to facilitate the trade in goods, while others use electronic accounting systems to offer help (Seyfang and Longhurst, 2015). For example, Brazilian community banks issue "social" currency for economic development and citizen empowerment (De Melo Neto Segundo, 2010). 
Community currencies face several major challenges, however: (1) the currency exchange is based on personal interactions, so the community may not grow to maturity; (2) the use of CCs may wane over time; and (3) the success of a CC movement is difficult to measure (Seyfang and Longhurst, 2016). Despite these challenges, the use of community currencies is spreading rapidly in various regions of the world.

Cohousing: Cohousing is a growing type of GM. It is also bundled with other terms, such as alternative housing and ecohousing. It has received considerable attention from policy makers and industry. As a community development model, cohousing comprises six main characteristics: a participatory process, a community-focused design, common facilities, resident management, a non-hierarchical structure, and separate income sources (see Boyer, in press). Grassroots cohousing movements have emerged from the shared values of human-scale development, decentralization, empowerment, and the self-reliance of activists, builders, and academics (Smith, 2007). It is an increasingly popular form of development that combines elements of both collective and private ownership with the benefits of living in a community that shares spaces and activities (Sargisson, 2012). It offers economic, environmental, and social advantages over the current forms of development (Williams, 2008). Cohousing is believed to offer answers to many of the problems that modern society faces, including alienation, social isolation, and sustainable living. It generates first- and second-order learning underpinned by a robust set of practices, institutions, and networks. Cohousing entails visions that are very different from the incumbent regimes. It emphasizes the use of renewable energy and less polluting materials.

Grassroots housing may diffuse in three ways: replication, up-scaling, and translation (Boyer, in press). Replication represents an expansion in the number of similar initiatives, while up-scaling denotes the expansion of a particular initiative. Translation, meanwhile, involves the sharing of experiences between niches and regimes. The autonomous house, for example, was considered the first self-sufficient residence to be built in the UK. The project achieves self-sufficiency in terms of energy generation, water harvesting, and sewage treatment without a connection to the usual utilities. Moreover, there is a resurgence of interest in alternative building materials - such as straw bale, wood, cob, reed, and thatchthat can be sourced locally. Pickerill and Maxey (2009) propose five necessary considerations for sustainable housing: (1) paying close attention to the current sustainability, (2) finding radical solutions, (3) considering sustainability as an integrated approach, (4) being more politically assertive, and (5) considering the scalability. Cohousing as a GI allows for experimentation with bold social and technological alternatives that are often inaccessible in the mainstream market (Boyer, in press). Even though cohousing projects have many sustainable outcomes, they face significant challenges in diffusing their ideas and practices beyond the niche and into the greater society (Seyfang, 2010). Like other grassroots initiatives, intermediaries play a significant role in the diffusion of cohousing (Boyer, 2015). Based on a survey of 60 cohousing residents and 65 demographically similar individuals, Markle et al. (2015) found that cohousing participants exhibit more socially supportive behaviours than their noncohousing peers. Thus, cohousing contributes to living standards at a reduced cost.

Agriculture: GMs in agriculture are the collaborative initiatives of small farmers, land managers, researchers, and civil societies. They aim to find solutions for sustainable development by challenging the existing agricultural regime (Hart et al., 2016; Hermans et al., 2016). Most grassroots agriculture movements promote sustainable agriculture (Hart et al., 2016), and many countries have set up national 
plans to support such initiatives. Moreover, agricultural GMs focus on alternative innovation movements initiated by small farmers (Kirwan et al., 2013). Cabannes (2012) argues that urban agriculture financing includes monetary and non-monetary resource mobilization and individual and collective savings, as well as subsidies, microcredits, and other loans. Moreover, the authors point out how the common funding options for grassroots agriculture movements are non-institutional lenders, credit from friends and family, and pesticide and seed traders. Policymakers can learn valuable lessons from the success of grassroots agriculture initiatives (Verma et al., 2004).

A key impediment to grassroots urban agricultural movements is the scarcity of farmland (Cabannes, 2012). Innovation is important for sustainable agriculture to provide adequate food, reduce adverse effects on the environment, and improve agriculture in rural areas (Kirwan et al., 2013; Odegard and van der Voet, 2014). Many small firms lack the resources and capacities to create their own innovations for commercialization. Grassroots agriculture projects, meanwhile, face difficulty in securing finance from conventional institutions due to issues such as drought, flood, and the rigid rules and regulations of standard financial mechanisms (Cabannes, 2012). Proper support is necessary for farmers to increase their income significantly. Pintadas Solar in Brazil, for example, achieved a twofold increase in farmers' incomes through a new irrigation system (Creech et al., 2014). Most international donor agencies and specialized financial institutions do not consider urban agriculture to be a substantive venture, while urban farmers are reluctant to apply for loans and subsidies (Cabannes, 2012). GMs in agriculture therefore need support from state and local agencies.

Organic food: The organic food movement stemmed from a desire to have healthy, local food economies rather than food industrialization (Seyfang and Smith, 2007). Organic food projects work as a means to support community integration and capacity building (Kirwan et al., 2013), but there is no proper evaluation framework to understand local organic food as a strategy for sustainable food consumption (Seyfang, 2007a). The significant consumption from industries and public sectors is immune to sustainable consumerism, but promoting local organic food is important to nurture a new sense of connection with the land (Smith, 2006). The desire for more sustainable production of healthier, betterquality food is the main motive for people to engage in organic food projects (White and Stirling, 2013). In the UK, for example, the Federation of City Farms and Community Gardens (FCFCG) has supported around a thousand community gardens (White and Stirling, 2013). Consumers understand the term sustainable food in many ways, however, due to the lack of a standard definition for it (Seyfang, 2007b). Organic food provision has been widely credited with changing the conventional production and consumption systems. For example, a small sustainable food NGO called East Anglia Food Link actively promotes local organic foods in places such as schools and hospitals (Seyfang and Smith, 2007).

Numerous organic food movements involve a large number of individuals, both directly and indirectly. While these movements create a relatively small number of paid jobs, there are significant volunteering opportunities. Such opportunities enable unemployed people to gain skills and work experience, thus increasing their potential in the competitive job market (Kirwan et al., 2013). Organic food projects also provide many disadvantaged people - such as the homeless, those with mental health problems, retirees, and students - with opportunities for personal development. Volunteers can therefore have varied backgrounds and motivations for participating. Organic food projects can, however, experience some unwanted incidences, such as the theft of tools, which may trigger volunteers to leave a movement 
(Kirwan et al., 2013). Although finding volunteers is a challenging task for organic food projects, they can bring together people who may not have otherwise met each other (Seyfang and Haxeltine, 2012). Members enjoy a social forum where people of different backgrounds can get to know and understand each other's values and norms (Kirwan et al., 2013).

\subsection{The Triple Tensions of Grassroots Innovation}

Scaling up, sustainability, and success are three highly interrelated issues, but they are not discussed together in the GI literature (Hossain, 2016). Connecting these three issues together, as shown in Figure 2, we label them collectively as the triple tensions of GI.

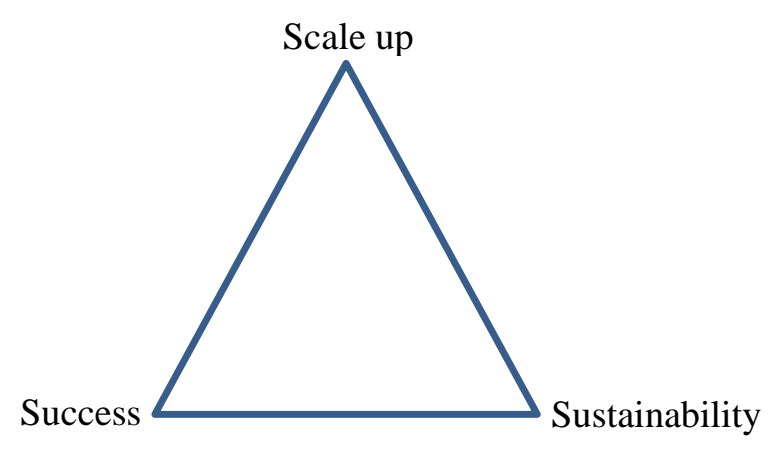

Figure 2. Triple Tension of grassroots innovation

Scaling up: Scalability is a pressing challenge for GIs and a key condition of sustainability (Gupta, 2012). Most GMs are not intended to be scaled up or replicated widely, yet they may still be adopted by governments (Seyfang, 2010). To scale up, GMs need to understand and mobilize the values held by the participants (Martin and Upham, 2015). How scaling up affects transformative change is also crucial to understand in context (Hermans et al., 2016). GMs work with a subservient mentality, especially when engaging with policymakers and large organizations (Hargreaves et al., 2013). Scaling up may be at a rhetoric level when claims about the movements are expressed as being good, bad, local, global, etc. Scaling up can be economic, political, and/or social (North, 2005). Local currencies, for example, circulate only within a defined territory. GMs are generally powerless, because the established actors tend to suppress them, yet they play a significant role in empowerment by providing collective action (see Schreuer, 2016).

Each GM has its own unique up-scaling approach that depends on the local context and available supports (Hermans et al., 2016). Local contexts, such as the population profile and political conditions, may play a crucial role in diffusing GMs (Feola and Butt, 2017). Networking also plays a key role in scaling up, and this can take place through different local projects, intermediary actors, and communities (Hargreaves et al., 2013). Hence, intermediary support is essential for them. For example, intermediaries can consolidate knowledge that enables CEs to develop tools and frameworks, as well as organize training for community members. The linkage across sectors (Smith and Seyfang, 2013) and the connections between individuals, communities, and the greater society are crucial for the scaling up of GMs (Korjonen-Kuusipuro et al., 2017). 
Sustainability: Sustainability is a key issue that upholds the high position of GI as a concept. GMs stem from the idea that existing consumption is unsustainable and asserts that people can live resource-poor yet satisfying lives (North, 2010). GMs contribute to sustainability both internally and externally. Internally speaking, they transfer skills to the new participants of GMs. Externally speaking, they contribute to sustainable consumption (Bradbury and Middlemiss, 2015). GIs have emerged to tackle the inequalities, injustices, and unsustainability of mainstream innovations (Martin et al., 2015), yet few studies have explored the role of GIs in sustainability (Hossain, 2016).

GMs are increasingly becoming a pivotal part of sustainability policy because of strong local institutions and locally originating actions (Burgess et al., 2003). The role of civil society is highly significant in sustainable consumption (Martin and Upham, 2015). GIs aimed at sustainability involve a radical revision of the existing regime to achieve a sustainable future (Hess, 2013). To achieve sustainability, it is essential to transform socio-technical systems to fulfil certain social functions, such as to provide energy, food, and transport (Gaziulusoy, 2015). In general, the role of GIs in sustainable production has been only modestly credited in science and policymaking (Ornetzeder and Rohracher, 2013). Furthermore, studies into sustainability transitions in various geographical contexts are also limited in the literature (Coenen and Truffer, 2012). However, GIs as alternative social, cultural, and economic models can help to achieve sustainable futures (Seyfang and Smith, 2007).

Success: Both the dimensions of policy and grassroots activism are essential for successful GIs (Wells, in press). Laws, regulations, policies, and citizen awareness and participation play key roles in the success of social-environmental enterprises (Creech et al., 2014). In an urban setting, Wolfram (in press) found that empowerment, embedded holistic innovation, community-oriented urban governance, and interaction between the niche and regime are four overarching issues for GIs. User participation is also imperative for GIs (Nielsen et al., 2016). According to Feola and Nunes (2014), the following five interdependent factors influence the success of GMs: (a) transition initiative characteristics, (b) members, (c) resources, (d) organization, and (e) context. However, the criteria for evaluating the success of GMs change over the development period. For example, an energy project originally intended for homeowners may become one that also delivers energy to non-residential (commercial) buildings with various improvements and financial support from large financial organizations (Hess, 2013). Some states also sometimes organize support and host training courses to accelerate GMs (Pansera and Owen, in press). A study of 56 food, mobility, and community energy movements by van den Heiligenberg et al. (2017) found that the success of GMs depends on the initiative itself, user involvement, cooperation with local and regional networks, policy, the dissemination of learning experience, etc.

Acheampong et al. (2016) argue that policy reform for GMs needs to be based on the social, economic, and political realities, because imported best practices may not be appropriate within the local reality. Some GMs become successful, while many others struggle to survive (Kirwan et al., 2013). Most studies into GMs have explored successful cases, which provide the knowledge to initiate similar projects in other localities. However, these studies can be counterproductive, because the presented cases offer limited insight into the detailed process and the challenges that these successful GMs faced (Hargreaves et al., 2013). 
Participatory approaches foster innovation by creating an awareness of the opportunities and providing information to the people who need it, thus supporting them and sharing best-practice experiences (Douthwaite et al., 2009). GMs play an important role in creating low-carbon communities within diverse contexts (Middlemiss and Parrish, 2010). They foster engagement with resourceful regime actors who can manage expectations by delivering tangible opportunities (Seyfang and Haxeltine, 2012). The development of skills and training programmes, policy, regulation, special workshops, and feedback lessons are useful in supporting GMs' contribution to the green economy (Boyer, 2014; Creech et al., 2014). Supporting GMs with insurance and security systems is also a useful support for success (Cabannes, 2012). Having a single place that covers relevant news, databases of projects, case studies, toolkits, handbooks, and online tools is also important to achieve the goals of GMs (Hargreaves et al., 2013). However, extra effort is needed to overcome barriers between niche and regime actors through means such as special workshops, feedback lessons (Smith, 2007), and bureaucratic streamlining of the relevant processes (Reinsberger et al., 2015).

In summary, GMs face difficulties in scaling up and becoming successful. They contribute to sustainability, but the magnitude of this contribution is not significant. GMs struggle to survive let alone transform into commercial ventures and need significant support from intermediary organizations. Quite often, GMs' contributions are not recognized by state and policy agents. In some sectors, such as solar power, the diffusion of GMs largely takes place due to consumers turning to entrepreneurs (Hyysalo et al., 2017). The links between GMs and mainstream science, technology, and innovation is also important for inclusive innovation (Fressoli et al., 2014), because GMs are distinctly different to each other (Feola, 2014). Despite this, GMs emerge from various sectors to tackle many pressing societal problems, often addressing sustainable consumption and behavioural change (Bradbury and Middlemiss, 2015).

\subsection{Driving and hindering factors for grassroots movements}

Driving factors: Experimentation with alternative technologies and collaboration between diverse stakeholders are far-reaching practices (Boyer, 2014). Increasing electricity prices, the declining cost of renewable technology, and governmental clean energy initiatives are driving GI (Wainstein and Bumpus, 2016). According to Akenji (2014), the key driving factors for GMs are legal, administrative, cultural, and commercial in nature. A close relationship with local and international partners is also essential to drive locally embedded small-scale GMs (Creech et al., 2014). Boyer (2015) argues that policymakers should engage GMs as part of official policy research and planning to support grassroots activities for networking between GMs and regime incumbents. GIs are also driven by social and environmental need. Moreover, they are grounded in local and collective values, and they provide a space for these values (Seyfang and Smith, 2007; Seyfang et al., 2014). An evolving technical identity, along with various community-building activities, provides a strong network to implement an initiative (de Vries et al., 2015). A niche practice becomes mainstream when sociotechnical landscapes start to threaten the established regime (Geels, 2004).

Most GMs are not driven by financial incentives but rather by wider social discourses like sustainability (Ornetzeder and Rohracher, 2013), involvement, passion, and enjoyment (Ross et al., 2012). Support from governments, international institutions, and NGOs are crucial for GIs (Creech et al., 2014). Limiting costs, building on existing technologies, networking, and building a community of members are also important for GMs (Ross et al., 2012). A geographical proximity that allows direct and frequent 
interaction between various local GMs is a further important factor for GMs (Feola and Nunes, 2014). Geographically dispersed and localised concentrations of counter-cultural practices, institutions, and networks also play an important role for GMs (Longhurst, 2015). Gupta (2012), meanwhile, argues that blending formal and informal sciences is essential for GI. Access to research and technological support is important for GMs if they are to develop and deploy novel technologies and processes (Creech et al., 2014). GMs also need to overcome financial and legal challenges promptly and focus on diffusing their practices over a broader perspective, sometimes by compromising on many of their more radical ideas in order to engage with existing regimes (Boyer, 2014). Varying financial incentives, the state's position, the political context, and market actors are also key factors for GMs (Oteman et al., 2014; Reinsberger et al., 2015).

Common driving forces for GMs are an ecological, anti-centralization approach and a preference for local community (Hoppe et al., 2015). Intermediaries play a crucial role in helping GMs to survive (Hargreaves et al., 2013; Geels and Deuten, 2006). They connect frequently isolated GMs with each other and wider regions (Howells, 2006). GMs often challenge the status quo, promote new forms of organization, and create alternative systems for provision (Feola and Nunes, 2014). Martin et al. (2015) argue that GMs within the sharing economy approach make contributions such as (1) coercion for GMs to become more commercial and (2) an interplay between the dynamics of GMs and the niches they reside in.

Hindering factors: Hindrances that GMs face fall into two categories: intrinsic and extrinsic (Seyfang and Smith, 2007). Intrinsic challenges relate to how GIs are internally organized, their skills requirements, resource requirements, and vulnerable situations such as funding cuts, the departure of key people, high turnover of volunteers, and changes in policies. GMs often lack the long-term commitment to accomplish their goals (Boyer, 2014). The extrinsic challenges, meanwhile, are context specificity, geographical rootedness, ideological commitment, and competition. Lack of funding is a key barrier to GMs developing, maintaining, and expanding (Cabannes, 2012). An awareness of raising funds, in addition to grants, is necessary for most GMs to thrive (White and Stirling, 2013). Hatzl et al. (2016) argue that GMs leverage a tightly-knit network of local actors and engage in informal learning, mainly due to a lack of intermediary actors. Most GMs do not document their tacit knowledge, such as the institutional learning, skills, and training that their members possess (Bradbury and Middlemiss, 2015). To solicit funding, GMs face bureaucracy, unclear procedures, a great deal of paperwork, a lack of information about the opportunities for credit and subsidies, difficulty in preparing funding applications, and onerous processes (Cabannes, 2012). They face difficulties in accessing research and technical support and dealing with local monitoring and enforcement bodies (Creech et al., 2014). Many GMs are also scattered, resulting in a major obstacle to developing strategies to gain formal support (Das, 2011). Most GMs are small and largely dependent on their members' capacities and motivations (Oteman et al., 2014).

A hybrid approach for innovation could involve linking global and local organizations, but this is yet to gain significance in practice (Ely et al., 2013). GMs are not sufficiently appreciated as a source of innovation (Ornetzeder and Rohracher, 2013), and they often fail to succeed due to a lack of sustained resource and institutional support (Seyfang et al., 2014). GMs also cannot develop robustness and resilience to some unexpected shocks, such as funding cuts, the departure of key personnel, high turnover rates for volunteers, changes in government policy, and burnout in activists (Bradbury and Middlemiss, 2015). Moreover, the mainstream actors tend to sideline GMs (Schreuer, 2016). GMs are influential in 
prompting a regime shift, but they alone cannot achieve this shift (Schot and Geels, 2008). Bradbury and Middlemiss (2015) indicate that most GMs spend up to $90 \%$ of their time on surviving and only $10 \%$ on developing their activities. Wheeler (2008) argues that GMs can overcome challenges by setting robust targets, monitoring their activities closely, developing a comprehensive set of actionable items, and implementing these items effectively.

The role of GMs in sustainable development is often undervalued (Creech et al., 2014). Setting clear and measurable key performance indicators (KPIs) for GMs can be challenging, but without such KPIs, it is difficult to communicate value propositions to communities, investors, target markets, and policymakers (Creech et al., 2014). Moreover, GMs are diverse in nature, so developing universal indicators to measure their success is challenging (Feola and Nunes, 2014). They are largely invisible to policy makers and involve less influential actors. Consequently, their potential remains underdeveloped.

\section{Discussion}

\subsection{Implications}

This study has reviewed the GI literature using a systematic review approach. It found that research into GI is dominant in five sectors, namely community energy, community currency, cohousing, agriculture, and organic food. It points out various issues related to the triple tensions (scaling up, sustainability, and success) that are faced by GMs. We find that GMs operate in a very harsh environment in terms of finance, policy support, and growth. Community energy is a dominant sector in the grassroots literature, but how it differs from other energy systems in terms of cost and technology is not clear in the literature. Community currency is also a popular practice among GMs. This inevitably differs from one location to another, so developing policies for community currency is challenging, and its influence is limited, even within a small geographical context. However, the emerging cryptocurrencies along with block chain technology could play a crucial role in peer-to-peer transactions and significantly influence community currency activities. Cohousing is also considered a GM, but research into cohousing has been conducted within various disciplines and under many other names. Consequently, cohousing in the context of GI literature is very limited, with it being scattered among various other fields and using different terms. Research into agriculture at the grassroots level has received most emphasis in urban settings, whereas understanding it in a rural setting is perhaps more important.

GMs experience the triple tensions of scaling up, sustainability, and success. Scaling up GMs is challenging for several distinct reasons, such as funding scarcity, the departure of key people, and a high turnover rate among community members. GMs often work and think in ways that are not conducive to scaling up much beyond their original conception. Moreover, they may also not be practical in a new context due to their rootedness in a particular community. Sustainability is a pivotal element of GMs, and its real contribution to sustainable development is still not recognizable. Most GMs make a limited contribution to sustainability when compared to other initiatives. The magnitude of their contribution to sustainability is difficult to measure, and this prevents them from attracting the attention of financial organizations, politicians, and policymakers. Most GMs are also non-profit ventures, so their success is not measurable in financial terms. 
One dilemma is whether the focus should be on small-scale urban projects to solve local problems in developed countries or emphasize rural settings, especially in developing countries. The evidence for the success of GMs is still largely anecdotal and narrative, and there are no well-developed key performance indicators (KPIs) to assess GMs. Whether GMs should be evaluated based on the criteria used for commercial ventures is still under debate. However, GMs show a socially transformative path toward sustainability.

Grassroots organizations do not carefully assess the scale up approach and how they contribute in sustainability. They need to consider the possibility of survival of their initiatives in the long term. Turning grassroots initiatives to commercial ventures should be consistently consider to success with their initiatives. Local and national governments tend not to consider grassroots initiatives in their policies. Multinationals do not encounter threats from the grassroots initiatives.

\subsection{Limitations and future research}

This study has several limitations. It provides a sectorial analysis and explores the tensions from three key issues of grassroots innovation. It has considered articles that clearly employ the grassroots innovation concept, but there may be other studies that explore the GI phenomenon through alternative concepts such as frugal innovation, bottom-up innovation, resource-constraints innovation, and bricolage. In addition, only two databases were used to search for relevant articles. This study also suggests a range of future research avenues, which are presented as follows. The definition and scope of the GI concept has not evolved much over time, even though studies into GI have explored various new sectors and avenues. The degree of sustainability contribution of most GMs is minuscule, and many GMs do not bring significant change to society. Many grassroots initiatives in the community energy sector, however, have made a valuable contribution to society. These initiatives cover various scales and models, and many of them have been explored from the perspectives of other disciplines, such as the mainstream energy research discipline.

Studies into GI are very scattered in the current literature. It is also concerning that a handful of scholars dominate in this discipline. Moreover, geographical research contexts are also limited. Even though the GI phenomenon has been researched over the last two decades, the number of studies is still relatively small, as we can see from this review study. It is essential for a wide range of scholars to explore the GI phenomenon over various geographical contexts to enrich this research field. The role of technology and how community members develop user-technology relations are also underemphasized in the current literature. Despite its high promise, limited attention has been paid to civic energy communities. Moreover, there is limited information on the demand for credit and the repayment capacity of GMs in the literature (Cabannes, 2012).

Emerging cryptocurrencies, such as Bitcoin and Ethereum, may allow community members to execute transactions that could diminish the use of current community currencies. It will be interesting to explore what value cryptocurrency can bring to community currency practices. Business models are also rarely discussed in the GI literature. GMs need to shift, improve, and modify their original business models for the commercial stage. It would therefore be valuable to explore GMs from the business model perspective. 
Studies into GMs have explored several sectors, but some cases have been repeatedly used in different studies. To enrich the discipline, it is important to explore various sectors using fresh cases. The GI literature also lacks a theoretical framing. Most studies are narrations of successful cases. To develop grassroots innovation as a well-established discipline, we need to develop typologies, models, frameworks, and theories so that scholars, practitioners, and policymakers can easily understand various facets of frugal innovation.

\section{References}

Acheampong, E. N., Swilling, M., and Urama, K. (2016). Sustainable urban water system transitions through management reforms in Ghana. Water Resources Management, 30(5), 1835 - 1849.

Akenji, L. (2014). Consumer scapegoatism and limits to green consumerism. Journal of Cleaner Production, 63, 13-23.

Anderson, C. R., and McLachlan, S. M. (2012). Exiting, enduring and innovating: Farm household adaptation to global zoonotic disease. Global Environmental Change, 22(1), 82-93.

Annarelli, A., Battistella, C., and Nonino, F. (2016). Product service system: A conceptual framework from a systematic review. Journal of Cleaner Production, 139, 1011-1032.

Bailey, I., Hopkins, R., and Wilson, G. (2010). Some things old, some things new: The spatial representations and politics of change of the peak oil relocalisation movement. Geoforum, 41(4), 595605.

Boyer, R. (2014). Sociotechnical Transitions and Urban Planning a Case Study of Eco-Cohousing in Tompkins County, New York. Journal of Planning Education and Research, 34(4), 451-464.

Boyer, R. H. (2015). Grassroots innovation for urban sustainability: comparing the diffusion pathways of three ecovillage projects. Environment and Planning A, 45, 320-337.

Boyer, R. H. (in press). Intermediacy and the diffusion of grassroots innovations: The case of cohousing in the United States. Environmental Innovation and Societal Transitions. https://doi.org/10.1016/j.eist.2017.08.001

Bradbury, S., and Middlemiss, L. (2015). The role of learning in sustainable communities of practice. Local Environment, 20(7), 796-810.

Cabannes, Y. (2012). Financing urban agriculture. Environment and Urbanization, 24(2), 665-683.

Collom, E. (2005). Community currency in the United States: the social environments in which it emerges and survives. Environment and Planning A, 37(9), 1565-1587.

Creech, H., Paas, L., Gabriel, G. H., Voora, V., Hybsier, C., and Marquard, H. (2014). Small-scale social-environmental enterprises in the green economy: supporting grassroots innovation. Development in Practice, 24(3), 366-378.

Das, K. (2011). Indian rural clusters and innovation: challenges for inclusion. Economics, Management, and Financial Markets, 6 (1), 283-301.

De Melo Neto Segundo, J. J. (2010). Associative community banks in Brazil. Journal of Labor and Society, 13(1), 61-76.

de Vries, G. W., Boon, W. P., and Peine, A. (2015). User-led innovation in civic energy communities. Environmental Innovation and Societal Transitions, 19, 51-65.

Douthwaite, B., Beaulieu, N., Lundy, M., and Peters, D. (2009). Understanding how participatory approaches foster innovation. International Journal of Agricultural Sustainability, 7(1), 42-60. 
Ely, A., Smith, A., Stirling, A., Leach, M., and Scoones, I. (2013). Innovation politics post-Rio+ 20: hybrid pathways to sustainability?. Environment and Planning C: Government and Policy, 31(6), 1063-1081.

Feola, G., and Butt, A. (2017). The diffusion of grassroots innovations for sustainability in Italy and Great Britain: an exploratory spatial data analysis. The Geographical Journal, 183(1), 16-33.

Feola, G., and Nunes, R. (2014). Success and failure of grassroots innovations for addressing climate change: the case of the transition movement. Global Environmental Change, 24, 232-250.

Feola, G. (2014). Narratives of grassroots innovations: a comparison of voluntary simplicity and the transition movement in Italy. International Journal of Innovation and Sustainable Development, 8(3), 250-269.

Gaziulusoy, A. I. (2015). A critical review of approaches available for design and innovation teams through the perspective of sustainability science and system innovation theories. Journal of Cleaner Production, 107, 366-377.

Geels, F. W. (2004). From sectoral systems of innovation to socio-technical systems: Insights about dynamics and change from sociology and institutional theory. Research Policy, 33(6), 897-920.

Geels, F., and Deuten, J. J. (2006). Local and global dynamics in technological development: a sociocognitive perspective on knowledge flows and lessons from reinforced concrete. Science and Public Policy, 33(4), 265-275.

Grabs, J., Langen, N., Maschkowski, G., and Schäpke, N. (2016). Understanding role models for change: a multilevel analysis of success factors of grassroots initiatives for sustainable consumption. Journal of Cleaner Production, 134, Part A, 98-111.

Gupta, A. K. (2012). Innovations for the poor by the poor. International Journal of Technological Learning, Innovation and Development, 5(1-2), 28-39.

Hargreaves, T., Hielscher, S., Seyfang, G., and Smith, A. (2013). Grassroots innovations in community energy: The role of intermediaries in niche development. Global Environmental Change, 23(5), 868880.

Hart, A. K., McMichael, P., Milder, J. C., and Scherr, S. J. (2016). Multi-functional landscapes from the grassroots? The role of rural producer movements. Agriculture and Human Values, 33(2), 305-322.

Hatzl, S., Seebauer, S., Fleiß, E., and Posch, A. (2016). Market-based vs. grassroots citizen participation initiatives in photovoltaics: A qualitative comparison of niche development. Futures, 78, 57-70.

Haxeltine, A., and Seyfang, G. (2009). Transitions for the People: Theory and Practice of 'Transition' and 'Resilience' in the UK's Transition Movement. Tyndall Centre for Climate Change Research, Working Paper, 134.

Heiskanen, E., Jalas, M., Rinkinen, J., and Tainio, P. (2015). The local community as a "low-carbon lab": Promises and perils. Environmental Innovation and Societal Transitions, 14, 149-164.

Hermans, F., Roep, D., and Klerkx, L. (2016). Scale dynamics of grassroots innovations through parallel pathways of transformative change. Ecological Economics, 130, 285-295.

Hess, D. J. (2013). Industrial fields and countervailing power: The transformation of distributed solar energy in the United States. Global Environmental Change, 23(5), 847-855.

Hodson, M., and Marvin, S. (2010). Can cities shape socio-technical transitions and how would we know if they were?. Research Policy, 39(4), 477-485.

Hoppe, T., Graf, A., Warbroek, B., Lammers, I., and Lepping, I. (2015). Local governments supporting local energy initiatives: Lessons from the best practices of Saerbeck (Germany) and Lochem (The Netherlands). Sustainability, 7(2), 1900-1931. 
Hossain, M and Anees-ur-Rehman, M. (2016). Open innovation: An analysis of twelve years of research, Strategic Outsourcing: An International Journal, 9(1), 22-37.

Hossain, M. (2016). Grassroots innovation: A systematic review of two decades of research. Journal of Cleaner Production, 137, 973-981.

Howells, J. (2006). Intermediation and the role of intermediaries in innovation. Research Policy, 35(5), 715-728.

Hyysalo, S., Johnson, M., and Juntunen, J. K. (2017). The diffusion of consumer innovation in sustainable energy technologies. Journal of Cleaner Production, 162, S70-S82.

Jain, A., and Verloop, J. (2012). Repositioning grassroots innovation in India's Sand T policy: from divider to provider. Current Science, 103(3), 282-285.

Kirwan, J., Ilbery, B., Maye, D., and Carey, J. (2013). Grassroots social innovations and food localisation: An investigation of the Local Food programme in England. Global Environmental Change, 23(5), 830-837.

Klein, S. J., and Coffey, S. (2016). Building a sustainable energy future, one community at a time. Renewable and Sustainable Energy Reviews, 60, 867-880.

Korjonen-Kuusipuro, K., Hujala, M., Pätäri, S., Bergman, J. P., and Olkkonen, L. (2017). The emergence and diffusion of grassroots energy innovations: Building an interdisciplinary approach. Journal of Cleaner Production, 140, 1156-1164.

Longhurst, N. (2015). Towards an 'alternative' geography of innovation: Alternative milieu, sociocognitive protection and sustainability experimentation. Environmental Innovation and Societal Transitions, 17, 183-198.

Marckmann, B., Gram-Hanssen, K., and Christensen, T. H. (2012). Sustainable living and co-housing: Evidence from a case study of eco-villages. Built Environment, 38(3), 413-429.

Markle, E. A., Rodgers, R., Sanchez, W., and Ballou, M. (2015). Social support in the cohousing model of community: a mixed-methods analysis. Community Development, 46(5), 616-631.

Martin, C. J., and Upham, P. (2016). Grassroots social innovation and the mobilisation of values in collaborative consumption: A conceptual model. Journal of Cleaner Production, 134, 204-213.

Martin, C. J., Upham, P., and Budd, L. (2015). Commercial orientation in grassroots social innovation: Insights from the sharing economy. Ecological Economics, 118, 240-251.

Middlemiss, L., and Parrish, B. D. (2010). Building capacity for low-carbon communities: The role of grassroots initiatives. Energy Policy, 38(12), 7559-7566.

Middlemiss, L. (2011). The effects of community-based action for sustainability on participants' lifestyles. Local Environment, 16(3), 265-280.

Monaghan, A. (2009). Conceptual niche management of grassroots innovation for sustainability:The case of body disposal practices in the UK. Technological Forecasting and Social Change, 76(8), 10261043.

Nielsen, K. R., Reisch, L. A., and Thøgersen, J. (2016). Sustainable user innovation from a policy perspective: a systematic literature review. Journal of Cleaner Production, 133, 65-77.

North, P. (2010). Eco-localisation as a progressive response to peak oil and climate change-a sympathetic critique. Geoforum, 41(4), 585-594.

Odegard, I. Y. R., and Van der Voet, E. (2014). The future of food-scenarios and the effect on natural resource use in agriculture in 2050. Ecological Economics, 97, 51-59. 
Ornetzeder, M., and Rohracher, H. (2013). Of solar collectors, wind power, and car sharing: comparing and understanding successful cases of grassroots innovations. Global Environmental Change, 23(5), 56-867.

Oteman, M., Wiering, M., and Helderman, J. K. (2014). The institutional space of community initiatives for renewable energy: a comparative case study of the Netherlands, Germany and Denmark. Energy, Sustainability and Society, 4(1), 1-17.

Pansera, M., and Owen, R. (in press). Innovation for de-growth: A case study of counter-hegemonic practices from Kerala, India. Journal of Cleaner Production. https://doi.org/10.1016/j.jclepro.2016.06.197

Peine, A., Rollwagen, I., and Neven, L. (2014). The rise of the "innosumer"-rethinking older technology users. Technological Forecasting and Social Change, 82, 199-214.

Pickerill, J., and Maxey, L. (2009). Geographies of sustainability: low impact developments and radical spaces of innovation. Geography Compass, 3(4), 1515-1539.

Ross, T., Mitchell, V. A., and May, A. J. (2012). Bottom-up grassroots innovation in transport: motivations, barriers and enablers. Transportation Planning and Technology, 35(4), 469-489.

Reinsberger, K., Brudermann, T., Hatzl, S., Fleiß, E., and Poach, A. (2015). Photovoltaic diffusion from the bottom-up: Analytical investigation of critical factors. Applied Energy, 159, 178-187.

Sargisson, L. (2012). Second-Wave cohousing: A modern utopia?. Utopian Studies, 23(1), 28-56.

Schot, J., and Geels, F. W. (2008). Strategic niche management and sustainable innovation journeys: theory, findings, research agenda, and policy. Technology Analysis \& Strategic Management, 20(5), 537-554.

Schreuer, A. (2016). The establishment of citizen power plants in Austria: A process of empowerment?. Energy Research \& Social Science, 13, 126-135.

Seyfang, G. (2007a). Growing sustainable consumption communities: the case of local organic food networks. International Journal of Sociology and Social Policy, 27(3/4), 120-134.

Seyfang, G. (2007b). Cultivating carrots and community: local organic food and sustainable consumption. Environmental values, 16(1), 105-123.

Seyfang, G. (2010). Community action for sustainable housing: Building a low-carbon future. Energy Policy, 38(12), 624-7633.

Seyfang, G., and Haxeltine, A. (2012). Growing grassroots innovations: exploring the role of community-based initiatives in governing sustainable energy transitions. Environment and PlanningPart C, 30(3), 381- 400.

Seyfang, G., Hielscher, S., Hargreaves, T., Martiskainen, M., and Smith, A. (2014). A grassroots sustainable energy niche? Reflections on community energy in the UK. Environmental Innovation and Societal Transitions, 13, 21-44.

Seyfang, G., and Longhurst, N. (2013a). Desperately seeking niches: Grassroots innovations and niche development in the community currency field. Global Environmental Change, 23(5),881-891.

Seyfang, G., and Longhurst, N. (2013b). Growing green money? Mapping community currencies for sustainable development. Ecological Economics, 86, 65-77.

Seyfang, G., and Longhurst, N. (2016). What influences the diffusion of grassroots innovations for sustainability? Investigating community currency niches. Technology Analysis \& Strategic Management, 28(1), 1-23.

Seyfang, G., and Smith, A. (2007). Grassroots innovations for sustainable development: Towards a new research and policy agenda. Environmental Politics, 16(4), 584-603. 
Seyfang, G., Park, J. J., and Smith, A. (2013). A thousand flowers blooming? An examination of community energy in the UK. Energy Policy, 61, 977-989.

Smith, A., Hargreaves, T., Hielscher, S., Martiskainen, M., and Seyfang, G. (2016). Making the most of community energies: Three perspectives on grassroots innovation. Environment and Planning A, 48(2), 407-432.

Smith, A., Fressoli, M., and Thomas, H. (2014). Grassroots innovation movements: challenges and contributions. Journal of Cleaner Production, 63, 114-124.

Smith, A., and Seyfang, G. (2013). Constructing grassroots innovations for sustainability. Global Environmental Change, 5(23), 827-829.

Smith, A. (2006). Green niches in sustainable development: the case of organic food in the United Kingdom. Environment and Planning C: Government and Policy, 24(3), 439-458.

Smith, A. (2007). Translating sustainabilities between green niches and socio-technical regimes. Technology Analysis \& Strategic management, 19(4), 427-450.

Thomas, D. R. (2006). A general inductive approach for analyzing qualitative evaluation data. American Journal of Evaluation, 27(2), 237-246.

Tranfield, D., Denyer, D., and Smart, P. (2003). Towards a methodology for developing evidenceinformed management knowledge by means of systematic review. British Journal of Management, 14(3), 207-222.

Vergragt, P. J., and Brown, H. S. (2012). The challenge of energy retrofitting the residential housing stock: grassroots innovations and socio-technical system change in Worcester, MA. Technology Analysis \& Strategic Management, 24(4), 407-420.

Vergragt, P. J., Dendler, L., de Jong, M., and Matus, K. (2016). Transitions to sustainable consumption and production in cities. Journal of Cleaner Production, 134, 1-12.

Verma, S., Tsephal, S., and Jose, T. (2004). Pepsee systems: grassroots innovation under groundwater stress. Water Policy, 6(4), 303-318.

Wainstein, M. E., and Bumpus, A. G. (2016). Business models as drivers of the low carbon power system transition: a multi-level perspective. Journal of Cleaner Production, 126, 572-585.

Walker, G., and Cass, N. (2007). Carbon reduction, 'the public' and renewable energy: engaging with socio- technical configurations. Area, 39(4), 458-469.

Walker, G., Devine-Wright, P., Hunter, S., High, H., and Evans, B. (2010). Trust and community: Exploring the meanings, contexts and dynamics of community renewable energy. Energy Policy, 38(6), 2655-2663.

Wells, P. (in press). Degrowth and techno-business model innovation: The case of Riversimple. Journal of Cleaner Production. https://doi.org/10.1016/j.jclepro.2016.06.186

Wheeler, S. M. (2008). State and municipal climate change plans: the first generation. Journal of the American Planning Association, 74(4), 481-496.

White, R., and Stirling, A. (2013). Sustaining trajectories towards Sustainability: Dynamics and diversity in UK communal growing activities. Global Environmental Change, 23(5), 838-846.

Williams, J. (2008). Predicting an American future for cohousing. Futures, 40(3), 268-286.

Wolfram, M. (in press). Cities shaping grassroots niches for sustainability transitions: Conceptual reflections and an exploratory case study. Journal of Cleaner Production, 173, 11-23.

Yalçın-Riollet, M., Garabuau-Moussaoui, I., and Szuba, M. (2014). Energy autonomy in Le Mené:A French case of grassroots innovation. Energy Policy, 69, 347-355. 